\title{
SELING
}

Jurnal Program Studi PGRA

ISSN (Print): 2540-8801; ISSN (Online):2528-083X

Volume 5 Nomor 2 Juli 2019

P. 161-168

\section{EFEKTIVITAS KEGIATAN OUTBOUND FUN ESTAFET UNTUK MENINGKATKAN PERKEMBANGAN SOSIAL ANAK DI TAMAN KANAK-KANAK AL-JANNAH TARUSAN KABUPATEN PESISIR SELATAN}

Rolla Afriza Yeni ${ }^{1}$, Prima Aulia ${ }^{2}$

1,2 Universitas Negeri Padang

rollaafrizayeni@gmail.com

\begin{abstract}
The purpose of this study was determine the effectiveness of relay outbound fun activities on improving social development of children in aljannah tarusan kindergarten kabupaten pesisir selatan. In this study quantitative research in the form of quasy experiments was used. The result showed that according ti the analysis of indpendent data from the sample t-test using SPSS for windows 23, previously the normality and hmogenity test were carried out, and also with the N-Gain score test. The result obtained sig (2tailed) 0,012<0,05 means that there is a significant (significant) difference in effectiveness between the treatment given by the teacher and the treatmeant of relay outbound fun activities to improve children's social development. Based on the analysis of the result of the hypothesis test and the effect test, it was concluded that the effective relay outbound activity was effective to enhance the social development of children at al-jannah Tarusan Kindergarten, Kabupaten Pesisir Selatan.
\end{abstract}

Keywords: Relay fun Outbound Activities; Social Development.

\begin{tabular}{ccc} 
Submission & Revised & Publication \\
\hline 12 February 2019 & 13 May 2019 & 30 July 2019
\end{tabular}

\section{LATAR BELAKANG}

Pendidikan adalah modal utama untuk mempersiapkan generasi yang berkualitas dan berniai tinggi. Untuk menciptakan generasi bangsa yang bernilai tinggi dan berbudi pekerti sesuai dengan norma maka dibutuhkan pendidikan sejakusia dini. Pendidikan anak usia dini sangat penting, karena anak-anak berada pada masa tahap perkembangan dan pertumbuhan yang sangat pesat. 
Pengembangan pondasi dasar anak dapat dikembangkan melalui pendidikan taman kanak-kanak. Perkembangan fisik-motorik, intelektual, emosional, maupun spiritual dipengaruhi pendidikan prasekolah (Setiawan, 2018)

Pendidikan anak usia dini adalah suatu usaha dan upaya pemberian stimulus untuk mengembangkan seluruh aspek -aspek perkembangan anak agar berkembang optimal dan siap untuk kehidupannya dimasa depan, salah satu aspek yang perlu di kembangkan adalah perkembangan sosial anak. Menurut (Suryana, 2016) pendidikan anak usia dini bertujuan untuk menanamkan dasar awal menuju perkembangan anak, seperti perkembangan sikap, perilaku, pengakuan, keterampilan, dan kreativitas anak untuk perkembangan anak selanjutnya.

(Suyadi \& Ulfah, 2015) menyatakan pendidikan anak usia dini adalah suatu usaha yang dilakukan oleh guru yang telah direncanakan yng bertujuan untuk mengembangkan potensi anak secara menyeluruh dan optimal.

Salah satunyayaitu perkembangan sosial anak, karena perkembangan sosial adalah kemampuan awal yang perlu diiliki, agar anak mampu berinteraksi dan bersosisalisi dengan lingkungan sekitarnya. Menurut (Eliza, 2017) perkembangan sosial meliputi alur atau langkah langkah dalam menyesuaikan diri dengan aturan yang ada seperti aturan dalam kelompok, norma serta kebiasaan-kebiasaan disekitar kita. Kemampuan sosial tersebut harus mulai dikembangkan sejak usia dini. Kemampuan sosial adalah salah satu aspek yang perlu dimiliki anak, karena dengan kemampuan sosial ini anak akan mampu bersosialisasi serta beradaotasi dengan lingkungan sekitarnya. Dengan demiian kemampuan sosial meruapkan kemampuan untuk menyesuaikan diri, saling mengerti, saling berkomunikasi, serta bekerja sama. Oleh sebab itu, kemampuan sosial sangat penting dkembangkan agar anak memiliki modal awal untuk menghadapi kehidupan sosial memiliki karakter yang baik untuk masa yang akan datang.

Menurut (P.Perdani, 2013) keterampilan sosial adalah kemampuan seseorang dalam berkomunikasi dengan lingkungannya, bekerja sama dalam kelompok, berbagi dengan sesama,ikut erta dan menyesuaikan diri, serta disiplin sesuai dengan norma dan aturan yang ada disekitar kita.

Berdasarkan fakta yang terjadi dilapangan, peneliti menemukan berbagai masalah perkembangan sosial anak di TK Al-Jannah Tarusan Kabupaten Pesisir Selatan, hail ini terlihat ketika proses pembelajaran berlangsung dan saat anak - anak bermain dengan teman - temannya disekolah. Anak - anak masih banyak yang tidak mau saling berbagi seperti tidak mau meminjamkan alat tulis kepada temannya, kecuali itu teman dekatnya. Selain itu anak belum mampu untuk disiplin dengan aturan - aturan yang ada dalam kelompok bermain, bahkan ada anak yang suka mentertawakan dan mengejek temannya yang sedang kesusahan, menangis, sakit.

Permasalahan - permasalahan tersebut disebabkan oleh beberapa faktor yang menghambat sosial anak, salah satunya yaitu kurangnya variasi guru dalam melaksanakan kegiatan - kegiatan yang dilakukan untuk mengembangkan sosial anak, serta media dan kegiatan yang kurang menarik anak, sehingga anak merasa bosan dan monoton dalam pelaksanaan belajar(Dewi, 2014).

162 | Volume 5, Nomor 1, Januari 2019 || SELING: Jurnal Program Studi PGRA 
Dalam meningkatkan perkebangan sosial anak, dari beberapa cara untuk mengatasi permasalahan tersebut, salah satunya adalah aktivitas kegiatan bermain yang bermakna seperti diluar rungan dengan inovasi - inovasi yang menarik perhatian anak seperti outbound. Outbound merupakan kegiatan berupa permainan yang dilakuakan diruangan terbuka dengan memberikan pengelaman langsung kepada anak melalui tantangan, petualangan dan rekreasi.

Kegiatan outbound bisa digunakan untuk usia atau tingkat pendidikan apa saja, seperti anak- anak, remaja, dewasa. Ada berbagai macam bentuk outbound, seperti permainan, tantangan, rintangan, pembelajaran, petualangan, menyesuaikan dengan tujuan diadakannya outbound. Outbound bisa disebut sebagai kegiatan outdoor yang bersifat petualangan dengan berbagai macam tantangan yang menarik, yang lebih disebut sebagai kegaiatn belajar sambil bermain. (Mayangsari, Sari, \& Munaila, 2017)

Langkah - langkah yang perlu diperhatikan dalam pelaksanaan outbound menurut (Rocmah \& Sidoarjo, 2012) adalah pada tahap persiapan ada beberapa hal yang harus dilakukan atau disiapkan oleh guru, yaitu 1) guru menentukan atau memilih bentuk kegiatan. 2) guru menentukan waktu pelaksanaan. 3) guru mempersiapkan peralatan yang digunakan. Sedangkan daalam pelaksanaannya, 1) guru menjadikan anak menjadi beberapa kelompok. 2) guru menjelaskan tugas dan aturan dalam kegiatan. Untuk tahap terakhir, guru merewiew seluruh kagitan anak selama bermain.

Kegiatan outbound terbagi atas 2 bentuk, yaitu: 1) Real Outbound yaitu outbound yang penuh dengan tantangan yang sulit dan membutuhkan ketahanan yang kuat dan lebih menunjukan perkembangan motorik kasar. 2) Fun Outbound/Semi Outbound, yaitu kagiatan outbound yang pelaksanaannya berupa permainan ringan, tantangan yang ringan, menyenagkan, namun tetap bermanfaat bagi perkembangan pesertanya, khususnya dari sisi sosial dan kerja sama (Susanta, 2010)

Darai berbagai bentuk outbound salah satu dari kegiatan outbund yang mampu meningkatkan perkembangan sosial dan sesuai dengan usia anak usia dini adalah kegiatan fun oubound seperti outbound fun estafet, outbound ini merupakan outbound dengan variasi permainan yang dilaksanakan dengan memberikan rintangan dan tantangan dalam permainan, dilaksanakan secara berkelompok, dengan tujuan untu melatih kerja sama, kedisiplinan, interaksi sosial dalam kelompok.

Sesuai dengan penjelasan tersebut, maka peneliti berpikir untuk mencari alternatif penyelesaian masalah perkembangan sosial anak melalui kegiatan outbound fun estafet. Upaya pemecahan masalah tersebut dengan melakukan penelitian eksperimen yang berjudul "Efektivitas Kegiatan Outbound Fun Estafet untuk Meningkatkan Perkembangan Sosial Anak di Taman Kanak - Kanak Tarusan Kabupaten Pesisir Selatan".

\section{METODE PENELITIAN}

Volume 5, Nomor 2, Juli 2019 || SELING: Jurnal Program Studi PGRA | 163 
Berdasarkan fakta masalah yang ada, jenis penelitisn yang digunakan dalam penelitian ini adalah penelitian kuantitatif dengan mtode eksperimen dalam bentuk eksperimen semu (quasy eksperimen). Menurut (Sugiyono, 2013) "metode penelitian eksperimen dapat diartikan sebagai bentuk pelaksanaan penelitian yang digunakan untuk menemukan pengaruh suatu perlakuan terhadap yang lain dalam keadaan terkendalikan".

\section{Tabel 1.}

Desan Penelitian

\begin{tabular}{|l|l|c|c|}
\hline Kelompok & \multicolumn{1}{|c|}{ Pre-test } & Perlakuan & Post-test \\
\hline Eksperimen & $O_{1}$ & $\mathrm{X}$ & $O_{2}$ \\
\hline Kontrol & $O_{3}$ & - & $O_{4}$ \\
\hline
\end{tabular}

Keterangan :

$O_{1}=$ Pre-test (data awal) kelas eksperimen

$\mathrm{O}_{2} \quad=$ Pre-test (data awal) kelas kontrol

$X \quad=$ Kelompok yang melakukan kegiatan Outbound Fun Estafet

$\mathrm{O}_{3} \quad=$ Post-test (hasil akhir) kelas eksperimen

$\mathrm{O}_{4} \quad$ Post-test (hasil akhir) kelas kontrol

1. Kelas eksperimen

Pembelajaran pada eklas eksperimen diberikan perlakuankegiatan outbound fun estafet. Dalam penelitian ini guru yang mengajar dikelas eksperimen adalah peneliti sendiri.

2. Kelas kontrol

Pembelajaran pada kelas kontrol perlakuan diberikan oleh guru kelas.

Populasi dalam penelitian ini adalah siswa TK Al-Jannah Tarusan Kabupaten Pesisir Selatan. Dikepalai oleh ibuk Elvi Sri Wahyuni, S.Pd. adapun teknik pengambilan sampel yang dilakuakan dalam penelitian ini adalah purposive sampling (sampel bertuuan). Sampel dalam penelitian ini adalah kelas muhammad sebagai kelas eksperimen dan kelas musa sebagai kelas kontrol.adapun jumlah sampel untuk setiap kelompok eksperimen dan kontrol adalah 15 orang anak.

Teknik pengumpulan data yang digunakan dalam penelitian ini adalah non tes, yaitu kuisioner (angket) dan dokumentasi. Instrumen ini menggunakan skala likert dengan format checklist untuk penilainnya. Dengan kriteria jawabannya yaitu sanga setuju, setuju, ragu-ragu, tidak setuju dan sangat tidak setuju. Masing - masing kriteria jawaban tersebut memiliki skor sesuai dengan pembagian itemnya, karena instrumen kuisioner ini menggunakan skala likert maka item dalam instrumen terbagi menjadi item favorable dan unfavorable.

Adapun teknik analisis data yang digunakan dalam penelitian ini adalah membandingkan perbedaan dari dua rata - rata nilai dengan mancari selisih nilai atau n-gain score post-test dengan pre-test masing - masing kelompok, sehingga 164 | Volume 5, Nomor 1, Januari 2019 || SELING: Jurnal Program Studi PGRA 
dilakukan dengan uji t (independent sampel t-test). Namun sebelum dilakukan uji ttest, dilakukan uji normalitas dan uji homogenitas dengan uji oneway anova dibantu dengan SPSS for windows 23. Apabila telah diketahui data berdistribusi normal adan bersifat homogen baru dilakukan analisis data menggunakan uji independent sampel t-test.

\section{HASIL DAN PEMBAHASAN}

Berdasarkan analisis dengan rumus uji independent sampel T-Test (uji-t) diperoleh mean kelas kontrol 14,2 dan mean kelas eksperimen 21,933 pada taraf signifikansi $\alpha=0,05$.

Tabel 2. Output group statistic

Group statistic

\begin{tabular}{|l|l|r|r|r|r|}
\hline & Kelompok & $\mathrm{N}$ & Mean & \multicolumn{1}{c|}{$\begin{array}{c}\text { Std. } \\
\text { Deviation }\end{array}$} & $\begin{array}{c}\text { Std. Error } \\
\text { Mean }\end{array}$ \\
\hline $\begin{array}{l}\text { Perkembangan } \\
\text { Sosial }\end{array}$ & Kontrol & 15 & 14,2000 & 7,36012 & 1,90038 \\
& & 15 & 21,9333 & 8,37058 & 2,16128 \\
\hline
\end{tabular}

Beradasarkan tabel output group statistic diatasa diketahui nilai rata - rata (mean) Ngain untuk kelas eksperimen adalah 21, 933.berikutnya untuk mengethui perbedaan pda kedua terdebut bermakn (signifikan) atau tidak, dilakukan penafsiran tabel output yang kedua:

Tabel 3. Output uji independent sampel T-test

Independent Samples Test

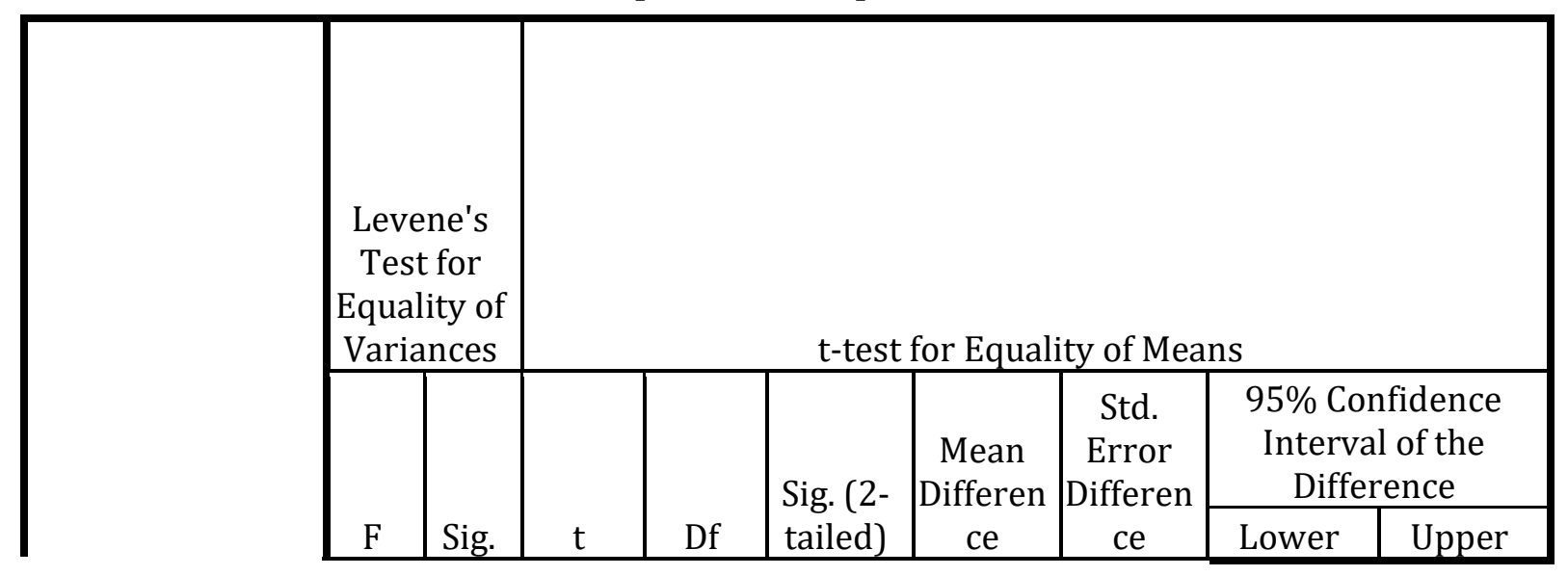

Volume 5, Nomor 2, Juli 2019 || SELING: Jurnal Program Studi PGRA | 165 


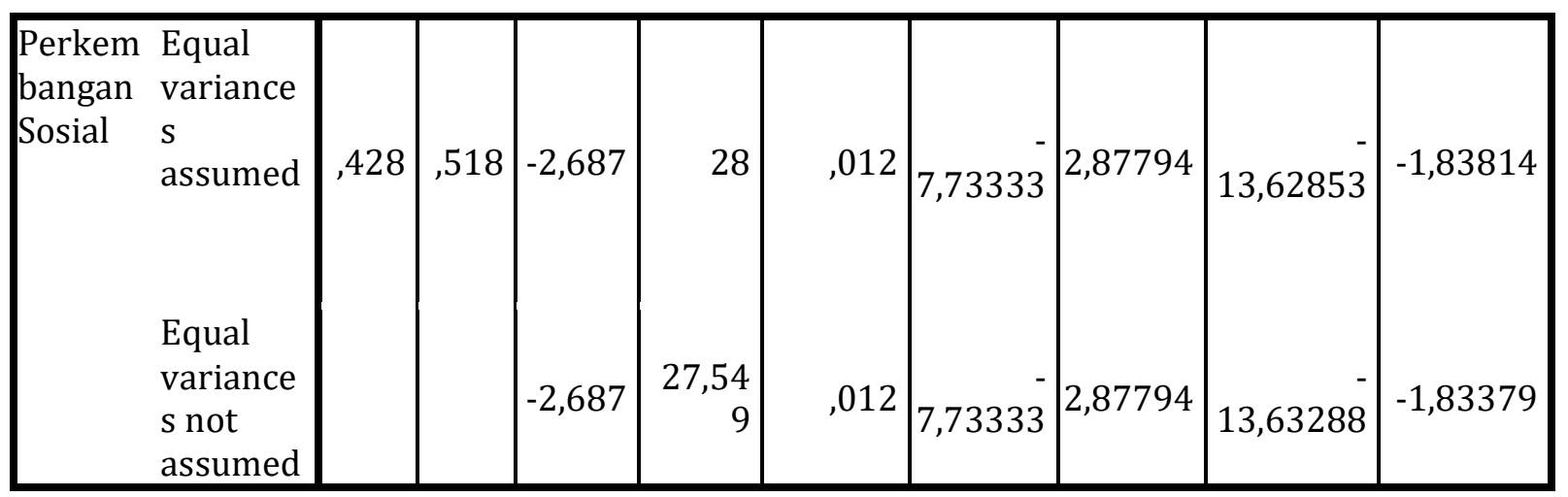

Berdasarkan tabel output tersebut diketahui nilai signifikansi (sig) pada levene's test equality of variance adalah sebesar 0,518 >0,05. Disimpulkan bahwa varians data $\mathrm{N}$-Gain untuk kelas eksperimen dan kelas kontrol adalah sama atau homogen. Kemudian berdasarkan tabel output diatas diketahui nilai sig (2-tailed) adalah sebesar $0,012<0,05$. Dengan demikian disimpukan terdapat perbedaan efektivitas yang signifikan (nyata) antara kegiatan outbound fun estafet dengan perlakuan yang diberikan guru dalam meningkatkan perkembanagan sosial anak di TK Al-Jannah tahun pelajaran 2019. Sedangkan untuk melihat seberapa efektif kegiatan outbound fun estafet untuk meningkatkan perkembangan sosial anak di TK Al-jannah Tarusan Kabupaten Pesisir Selatan digunakan teknik effectsize.

Effect size merupakan ukuran mengenai signifikansi perbedaan yang nyata hasil penelitian atau tingkat pengaruh suatu variabel dengan variabel yang lain. atau tingkat efek dari suatu variabel dengan variabel lainnya (Santoso, 2010). Dalam penelitian ini peneliti menggunakan perhitungan effect size Cohen's d untuk mengetahui besar pengaruhnya. Menurut Shaughessy dalam (Aulia, 2018) effect size yang sering digunakan dalam penelitian eksperimen adalah cohen's d, merupakan teknik mengukur perbedaan antara mean untuk tingkatan variabel indpendent dibagi dengan deviasi standar pada kelompok.

Berdasarkan rumus dari cohen's d tersebut didapatkan nilai effect size sebesar 2,854 berarti kegiatan outbound fun estafet efektif untuk meningkatkan perkembangan sosial anak di TK Al-Jannah Tarusan Kabupaten Pesisir Selatan. Berdasarkan hasil uji statistik dapat disimpulkan bahwa hipotesis kerja(Ha) diterima yaitu kegiatan outbound fun estafet efektif untuk meningkatkan perkembangan sosial anak di TK AlJannah Tarusan Kabupaten Pesisir Selatan.

\section{Pembahasan}

Outbound adalah bentuk kegiatan yang dilakukan di ruang terbuka atau outdoor, dengan tujuan memberikan pengalaman langsung. Outbound fun estafet ini merupakan kegiatan belajat sambil bermain di ruangan terbuka yang dilakukan secara berkelompok dan penuh tantangan dan menyenagkan.

Rochmah dalam (Isbayani, Sulastri, \& Tirtayani, 2015) outbound menggunakan pendekatan belajar exsperintal learning karena anak akan mendapatkan pengetahuan melalui pengalaman secara langsung yang dialaminya sendiri. Outbound membantu

166 | Volume 5, Nomor 1, Januari 2019 || SELING: Jurnal Program Studi PGRA 
anak untuk mengekspresikan diri dan emosinya, membantu dalam proses anak bersosialisasi dengan lingkungannya.

Selain itu (Sari \& Sagala, 2015) juga menyatakan dalam jurnal penelitiannya bahwa kegiatan outbound dapat mngembangkan kemampuan anak dalam berinteraksi sosial dengan lingkungan, baik orang tua, guru dan temannya serta outbound dapat membangun karakter yang baik untuk anak.

Berdasarkan tabel output group statistic hasil penelitian diatas diketahui nilai rata - rata (mean) gain score kelas eksperimen adalah 21,9333 untuk kelas kontrol adalah 14,2. Sesuai tabel output diatas diketahui nilai sig (2-tailed) adalah sebesar $0,012<0,05$. Disimpulkan Ho ditolah dan Ha diterima yang artinya terdapat perbedaan yang signifikan (nyata) antara kegiatan outbound fun estafet dengan perlakuan diberikan guru untuk meningkatkan perkembangan sosial anak di TK Aljannah Tarusan Kabupaten Pesisir Selatan tahun ajaran 2019. Selain itu, sesuai juga dengan hasil uji pengaruh (effect size) sebesar 2,85421 yang berarti tingkat pengaruhnya sangat tinggi, artinya kegiatan outbound fun estafet sangat berpengaruh atau sangat efektif untuk meningkatkan perkembangan sosial anak di TK Aljannah Tarusan Kabupaten Pesisir Selatan.

Hal ini sesuai dengan hasil penelitian (Mayangsari et al., 2017) yang menyatakan hasil penelitiannya bahwa terdapat pengaruh kegiatan outbound fun estafet dalam meningkatkan perkembangan sosial emosional anak usia 4-5 tahun di TK PGRI Burneh Bangkalan. Begitu juga dengan hasil penelitian (Suryana \& Yulsyofriend, 2011) yang menyatakan hasil penelitiannya, bahwa kaegitan outbund sangat berdampak positif dalam meningkatkan kepercayaan diri anak di TK Pertiwi VI Kota Padang. (Subiyanto \& Hasibuan, 2014) juga menyimpulkan hasil penelitian bahwa kegiatan outbound dapat dijadikan acuan dalam meningkatkan perkembangan sosial emosional anak di PPT Tanjung IX.

\section{SIMPULAN}

Sesuai hasil dan pembahasan diatas didapatkan kesimpulan kegiatan outbound fun estafet efektif untuk meningkatkan perkembangan sosial anak di TK Aljannah Tarusan Kabupaten Pesisir Selatan.

Kesimpulan ini didapatkan setelah melewati proses, yakni proses analisis data yang terdiri atas pengujian berupa asumsi, yakni uji normalitas dan uji homogenitas serta pengujian hipotesis. Uji hipotesis dilakukan menggunakan uji independent sampel t-test melalui bantuan program SPSS for windows 23. Dari analisis data tersebut ditarik kesimpulan hipotesis yang ditolak adalah hipotesis nihil (Ho) dan hipotesis yang diterima adalah hipotesis kerja (Ha), yang berbunyi "kegiatan outbound fun estafet efektif untuk meningkatkan perkembangan sosial anak di TK Aljannah Tarusan Kabupaten Pesisir Selatan". 


\section{DAFTAR PUSTAKA}

Aulia, P. (2018). Efektivitas Permainan Cak Bur Terhadap Peningkatan Interaksi Sosial Siswa Taman Kanak - Kanak. JURNAL PENDIDIKAN : Early Childhood, 2(2), $1-7$.

Dewi, Y. A. S. (2014). Analisis Implementasi Kurikulum Tingkat Satuan Pendidikan (KTSP) di Sekolah Dasar Negeri Pisang Candi 1 Malang. Modeling, 1(2), 94-109.

Eliza, D. (2017). Pengembangan Model Pembelajaran Karakter Berbasis Cerita Tradisional Minangkabau Untuk Anak Usia Dini. Pedagogik, 3, 153-163.

Isbayani, N. S., Sulastri, N. M., \& Tirtayani, L. A. (2015). Jurusan Bimbingan Konseling Fakultas Ilmu Pendidikan Universitas Pendidikan Ganesha e-Journal PG PAUD Universitas Pendidikan Ganesha, 3(1).

Mayangsari, D., Sari, evi dwi novita, \& Munaila, N. (2017). Peningkatan Perilaku Prososial pada Anak Usia 4-5 Tahun Melalui Kegiatan Outbound Fun Estafet. $P G$ PAUD Trunojoyo, 4, 115-132.

P.Perdani. (2013). Peningkatan Keterampilan Sosial Melalui Metode Bermain Permainan Tradisional Pada Anak TK B. JURNAL PENDIDIKAN PAUD, 7.

Rocmah, L. I., \& Sidoarjo. (2012). Model Pembelajaran Outbound Untuk Anak Usia Dini. PEDAGOGIA, 1(2), 173-188.

Santoso, A. (2010). Studi Deskriptif Effect Size Penelitian - Penelitian di Fakultas Psikologi. Jurnal Penelitian, 14(1), 1-17.

Sari, L. P., \& Sagala, A. C. D. (2015). Upaya Meningkatkan Kecerdasan Emosional Anak Usia Dini Melalui Outbound Halang Rintang di TK pgri 38 Taman Pekunden Semarang, 97-111.

Setiawan, A. (2018). Meningkatkan kemampuan berhitung anak usia dini melalui media pembelajaran matematika di ra ma'arif 1 kota metro. Seling:Jurnal Program Studi PGRA, 4, 181-188.

Subiyanto, M. H., \& Hasibuan, R. (2014). Pengaruh Kegiatan Outbound Terhadap Perkembangan. PG PAUD, Fakultas Ilmu Pendidikan Universitas Negeri Surabaya, $1-5$.

Sugiyono. (2013). Metode Penelitian Pendidikan Pendekatan Kuantitaif, Kualitatif, dan R\&D. Metode Penelitian Pendidikan Pendekatan Kuantitaif, Kualitatif, Dan R\&D. https://doi.org/10.1007/s13398-014-0173-7.2

Suryana, D. (2016). Pendidikan Anak Usian Dini, Stimulasi dan Aspek Perkembangan Anak (pertama). Jakarta: KENCANA.

Suryana, D., \& Yulsyofriend. (2011). Laporan Penelitian, Efektivitas Outbound Dalam Pengembangan Kepercayaan Diri Pada Anak TK Pertiwi VI Kota Padang. Padang. Susanta, A. (2010). Outbound Profesional. Yogyakarta: C.V ANDI OFFSET. Suyadi, \& Ulfah, M. (2015). Konsep Dasar PAUD. Bandung: PT Remaja Rosdakarya. 